\title{
Online Teaching Experience Sharing in Colleges and Universities
}

\author{
You Zhou* \\ School of Taizhou, Nanjing Normal University, Taizhou 225300, Jiangsu Province, China \\ *Corresponding author: You Zhou, 550569316@qq.com
}

\begin{abstract}
With the innovation and breakthrough in 5G technology and computer-related fields, the learning methods and education mode have ushered in the new age of transformation. Subsequently, the way of teaching is also changing from offline teaching to online teaching. At present, how to ensure the teaching quality of online teaching poses a great challenge to educators. This paper introduces the characteristics of the current online teaching platform and some experience in the process of online teaching in order to explore and improve together.
\end{abstract}

Keywords: Colleges and universities; Online teaching; Cloud-based classroom platform

Publication date: December 2021; Online publication: January 24, 2022

\section{Introduction}

Online teaching is one of the current methods of college teaching ${ }^{[1]}$. Teachers and students are facing great challenges from the online teaching practice carried out throughout the country. Under the current situation of lack of cognition of the law of online teaching, online teaching is carried out in a form close to daily reference. So, the teacher became the "anchor", and the main interactive activities of students in the live class are commendable ${ }^{[2]}$. When many colleges and universities resumed classes, due to the simultaneous influx of a large number of students, almost all of the classes became congested, thereby affecting the normal teaching.

Based on the current misunderstanding of personalization and social interaction, the neglect of learning design, the lack of application support for technical tools, and the confusion about the selection of massive educational resources are some of the factors. We can let students watch videos and other resources on the $\mathrm{Mu}$ class platform before class, and focus on the explanation and analysis in the form of live broadcast in class with a focus on the interaction with students. The author changed the strategy of using the existing online platform and decided to develop a customized online cloud-based classroom learning platform. This analysis focuses on students' learning and teaching quality.

\section{Online teaching experience}

\subsection{Selection of online platform}

The author's current teaching method is: Self developed learning platform + QQ screen sharing. When the author developed the platform, the author thought about the following problems that need to be solved urgently: How to make the platform simple and easy to use without increasing the difficulty of using the platform for teachers and students; How to improve the interaction between teachers and students; How to obtain students' feedback in time; How to check homework online and correct it in time; Most importantly, how to make online teaching not a mere formality. 
In order to solve the difficulty of using the platform, the page design and operation buttons of the platform are simplified and planar. In order to avoid the cumbersome authentication and registration of the learning platform on the network, when the platform is initialized, the student number, student name, student photo, student class situation, class name, class teacher, etc. are imported in advance. There is no need for teachers and students to register, enter the account number (job number or student number) and initialization password; all they need to do is enter the home page of the platform for teaching and learning with one click.

The learning information on the home page is clear at a glance, and the content that students are most concerned about is placed on the home page. The home page mainly includes modules such as the number of uploaded homework, the number of learning courseware, examination and practice status, notification message, homework feedback, learning list and so on. The homepage of the cloud-based classroom platform is shown in Figure 1.

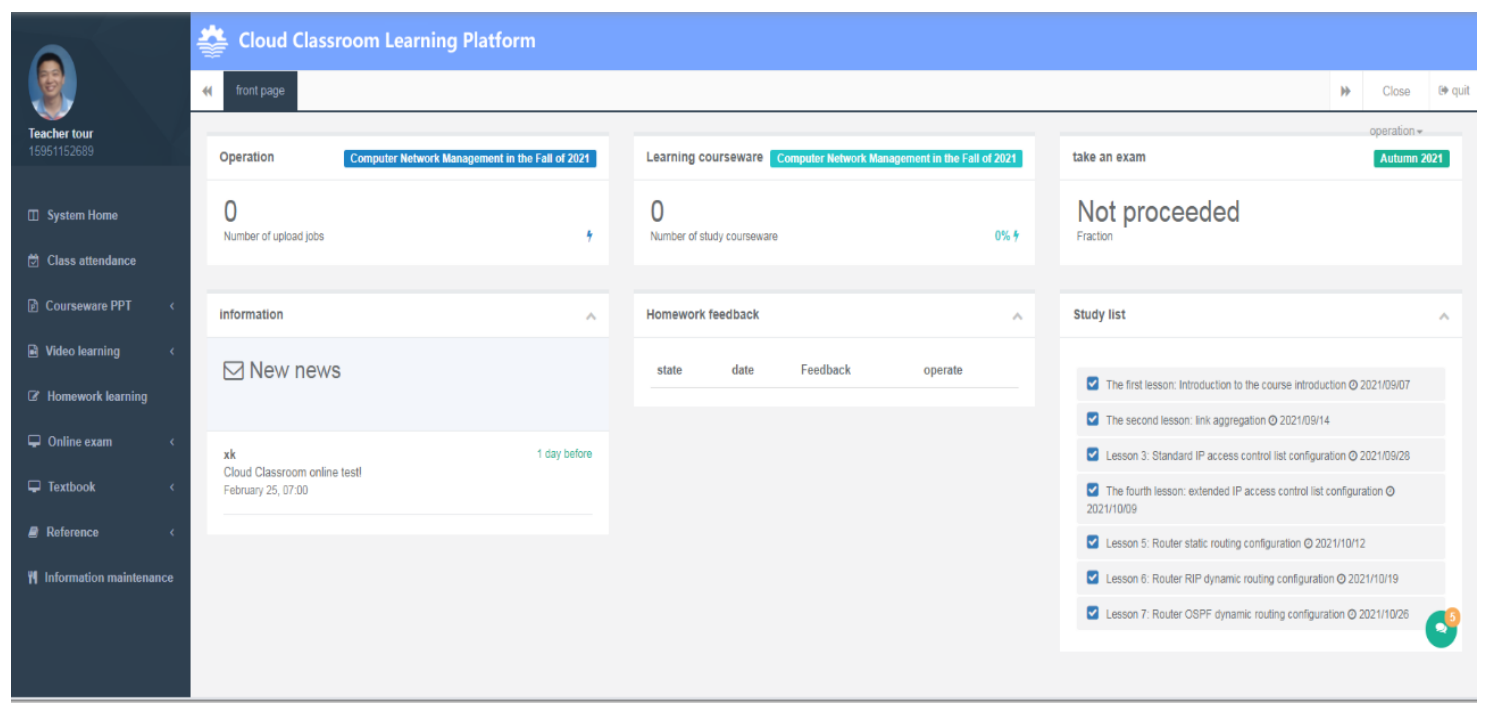

Figure 1. Homepage of cloud-based classroom platform

\subsection{Lesson preparation}

In the preparation of lessons for online teaching, we should first pay attention to each teaching link, the key points and difficulties of each teaching, and always pay attention to the students' learning level. Secondly, in the process of lesson preparation, we should pay attention to the characteristics of online teaching. Without the interactive link of offline blackboard writing, how can students better understand and master knowledge points? In order to solve this problem, teachers can sort out the knowledge points of each chapter, highlight the key points, eliminate the secondary contents, and record the video of teaching knowledge points. Finally, interactive learning links are designed around the key points and difficulties to make the learning atmosphere of online teaching vivid, so that students can actively participate in online classroom learning in an interactive atmosphere.

\subsection{Online teaching}

At ordinary times, some students have weak self-control and do not look at the computer. Therefore, targeted measures must be taken for online teaching to attract students' attention. In order to solve the problem of interaction between teachers and students, the platform is equipped with functions such as online discussion, message, test and question, and homework feedback. There is an online discussion module in the lower right corner of the platform, so teachers and students can give feedback in time according to the 
situation of the classroom. This method is only limited to students' active feedback. In the later stage, algorithm feedback based on face recognition can be added. For example, when students frown in class, they can feedback to the teacher in time. After online teaching, students can still interact with teachers through the platform if they have questions. In addition, teachers' online teaching does not interact with students in time and cannot understand the degree of students' knowledge absorption in time, which will lead to blindly "cramming" online teaching. Taking the learning time and the number of assignments as the standard, it will not only increase the additional burden on students, but also lead to new "learning anxiety" among students.

Regarding self-study and teaching, what to talk about, how to talk, how long to talk, and how to interact are worth thinking about by every teacher. We also need to deal with the relationship between teaching time and learning efficiency.

Live teaching is not the only way to teach online. In the author's teaching, the author tries not to use live broadcast avatars. Through QQ sharing screen and online voice explanation, the author focuses students' attention on knowledge content, rather than imitating the "online red live broadcast" on the network, narrowing the "online teaching" to "live lecture" [3].

In order to solve this problem, when teaching online, teachers can prepare open-thinking exercises for the course, and inform students in the first class that all learning operations on the platform will be recorded systematically as one of the criteria for judging learning efficiency. According to the login attendance, learning records and homework of students can be recorded on the learning platform ${ }^{[4]}$, students can be fairly scored as an effective record of the teaching process.

There must be videos in the teaching content, because the PPT content is a simplified version, which is not as detailed as the teaching materials. Even with electronic textbooks, students are easy to give up due to fatigue or lack of motivation, and videos can attract students' attention. If there are high-quality teaching videos online, teachers can explain the key parts of the chapters in simple language combined with concise PPT. This one is based on the experience of students' feedback. It is difficult to understand engineering professional courses only by listening to online courses, and the duration of the video is generally no longer than 10 minutes.

\subsection{Homework review}

In order to solve the problem of assignment and online submission, the platform is also equipped with the functions of online assignment and online submission. In order to review the homework in time, when the students successfully submit the homework to the platform, the platform will automatically send a WeChat message to the teacher to notify them to review in time. This function can customize the automatic notification on a personalized and regular basis to avoid notifications all the time.

\subsection{Teaching feedback}

In the teaching feedback, a few students do not bring notebooks and cannot learn online. In order to minimize the impact, the platform is compatible with mobile terminals, and students can learn online through mobile phones. If students in remote areas do not have basic network facilities and hardware facilities, this is an urgent problem to be considered and solved. Several suggestions have been made.

(1) Be able to install and skillfully use software before teaching online.

(2) If you choose an online teaching platform, do not just look at the operating instructions. Since the functions of the online teaching platform are complex, the operation interface is not very convenient and concise, and some buttons are not easy to find. These represent a great challenge for liberal arts teachers, but these skills can be gradually mastered through practical application. 
(3) During online teaching, teachers should wear earphones when giving lectures, and the noise of USB interface will be very low.

(4) During QQ screen sharing and voice live broadcasting, set "all staff mute" before class to avoid noise.

(5) Only open the application related to class to prevent the computer from crashing.

(6) Too much software may conflict with each other. A software or program is used as the main scheme, and the others are used as the standby schemes.

(7) Enter the classroom 10 minutes in advance, and adjust the teaching environment in advance.

\section{Conclusion}

Through online teaching and feedback on students' use of the platform, the author's deepest experience is: Online teaching focuses on learning and self-management ${ }^{[5]}$. Although online courses cannot replace offline courses, most of which need to be completed offline, some colleges and universities have put together experimental online teaching. The electrician and electronics experimental center of Southeast University took the lead in trying the experimental online teaching for "basic course of electrician and electronics," which provides an open online practice platform for students. This paper puts forward a new practical learning mode with experimental time fragmentation and the use of experimental resources on any occasion ${ }^{[6]}$.

We should keep a strong enterprising spirit, constantly try various technical functions and teaching process design, constantly iterate and improve with the accumulation of practice, and finally jointly explore and improve through open sharing and exchange, so as to finally contribute our positive efforts to the cause of education and teaching.

\section{Disclosure statement}

The author declares that there is no conflict of interest.

\section{References}

[1] Jia X, 2014, Research on the Management of "Intermediate Students" in Colleges and Universities. Journal of Kaifeng Institute of education, 2014(10): 83-84.

[2] Wang H, 2021, Construction Strategy and Practice Path of College Students' Sense of Acquisition of Online Ideological and Political Courses. Journal of Suzhou University of science and Technology (Social Science Edition), 38(3): 14-18.

[3] Xu M, Ye D, 2020, On Network Teaching in Colleges and Universities. Modern Vocational Education, 2020(26): 14-15.

[4] Lu J, NTU Thailand Institute Launched Customized “Cloud Classroom”. Taizhou Daily, March 25, 2020.

[5] Li L, Zhang Y, 2020, Quality Improvement Path of Academic Continuing Education in ApplicationOriented Universities: Practice Based on Anhui Continuing Education Online Platform. Journal of Suzhou University, 35(7): 19-23.

[6] Zheng L, Hu R, Du G, et al., 2021, Research and Exploration of New Technology Online Physical Experiment Platform. Laboratory research and exploration, 2021(5): 163-169. 